\title{
Başarılı Yaşlanma ve Kadın
}

\author{
Successful Aging and Woman
}

\author{
Çĭ̆dem Demir Çelebi*
}

\begin{abstract}
Öz
Yaşlı nüfus tüm dünyada olduğu gibi Türkiye'de de hızla artış göstermektedir. Artan yaşlı popülasyonu ve doğumda beklenen yaşam süresinin seksen yaşın üzerine çıkacak olması yaşlılık döneminde geçirilecek süreyi arttırmaktadır. Dolayısıyla yaşlıların üretime katılması ve daha aktif bir yaşlılık geçirmeleri giderek önem kazanmaktadır. Başarılı yaşlanma, yaşlıların bütüncül bir şekilde daha iyi yaşlanmaları açısından önemli ölçütleri tanımlamaktadır. Başarılı yaşlanmaya ilişkin faktörler incelendiğinde erkek ve kadın yaşlıların farklı deneyimlere sahip olduğu dikkat çekmektedir. Bu araştırmada kadınların başarılı yaşlanma deneyimleri kentleşme ve değişen aile yapısı, dul kalma ve yas, fizyolojik değişiklikler, psikolojik sorunlar, toplumsal ilişkiler, emeklilik ve yaşçılık kavramları çerçevesinde incelenerek kadınların daha başarılı bir yaşlanma evresi geçirmeleri için çeşitli öneriler sunulmaktadır.
\end{abstract}

\begin{abstract}
The elderly population is increasing rapidly in Turkey as in the whole world. The increasing elderly population and the fact that life expectancy at birth is predicted to exceed the age of 80 increase the time spent in old age. Therefore, it is increasingly important for the elderly to participate in production and to have a more active old age. Successful aging as a term defines important criteria for the elderly to age better in a holistic way. When the factors related to successful aging are
\end{abstract}

* Dr. Öğr. Üyesi. İstanbul Sabahattin Zaim Üniversitesi Eğitim Fakültesi, Rehberlik ve Psikolojik Danışmanlık Anabilim Dalı. cigdem.demircelebi@ gmail.com, 0000-0002-0886-9750

Başvuru: 27.03.2021

Kabul: 15.04.2021

DOI: 10.21798/kadem.2021.52
This work is licensed under the Creative Commons Attribution 4.0 International License.

Cite this article as: Demir Çelebi, Ç. (2021). Başarılı Yaşlanma ve Kadın, Kadem Kadın Araştırmaları Dergisi, Cilt 7, Sayı 1: 79-108. 
examined, it is noteworthy that male and female elderly people have different experiences. This study examines successful aging experiences of women within the framework of the concepts of urbanization and changing family structure, widowhood and grief, physiological changes, psychological problems, social relations, retirement, and aging. Various suggestions are presented for women to have a more successful aging phase.

\section{Extended Abstract}

When the literature on successful aging is examined, it is seen that there is not a single limited definition of the concept, and that many different components are discussed in defining it (Ebner \& Freund, 2007). According to Prudential (2015), successful aging is all about attitude: as long as the individual is optimistic, lives his life to the fullest, uses his potential fully, manages old age according to his own conditions, and also accepts whatever comes his way in life, he will age successfully.

The increase in the elderly population and the time spent in old age increase the importance of successful aging. According to the data of Turkish Statistical Institute (TURKSTAT) (2020), in the year 2019, $44.2 \%$ of the elderly population was male and $55.8 \%$ was female. Life expectancy at birth is also increasing gradually in Turkey. Today, the average life expectancy at birth in Turkey is 78.3. This value is 75.6 years for men and 81.0 years for women. In general, women live longer than men, and the difference in life expectancy at birth is calculated as 5.4 years. From this point of view, the concept of successful aging takes on a special significance for women. The fact that women exhibit different psychological and physiological characteristics from men also affects their aging experiences (Gökçe Sacred, \&Bal, t.y.). These characteristics lead women to have different experiences in old age in terms of physiological health, family life, social relations, production and retirement, and aging.

Urban population increased very rapidly between the years 1900-1950, when industrialization increased rapidly. The main reason for these migration movements to cities was the anxiety of finding a job. As a result of this great experience, women also started to participate in work life outside of the home. The involvement of women in work life outside empowered women in socioeconomic terms, facilitated access to services, and reduced gender role differences between men and women (Buz, 2009; İnce-Güney, 2014). However, it is noteworthy that the effectiveness of women in working life is still far behind compared to men. Even if women participate in work life, gender roles cannot be equal 
because they are expected to take responsibility for housework. There is also a need to make changes in the working environment of women (Tarhan, 2020).

Literature reveals that the elderly habitually witness the deaths of many loved ones, including their spouses, friends, and other family members (Shear et al., 2013). While the effects of grief are more intense in the first occurrences of death, it is seen that the well-being of the elderly increases as time passes (Luhmann et al., 2012). Although grief is a difficult situation to cope with, it is observed that elderly people who are more active in social life are mostly widows. It is thought that elderly people who have to care for their spouses due to illnesses could not participate in social life before their spouses died, and social participation increased due to the support of relatives and friends after the death of their spouse (Utz et al., 2002). However, lifestyle and habits of many years change with the death of the spouse, with whom the majority of life is spent together. Compliance problems can also be added to the sadness brought about by mourning.

With aging, the skin begins to dry and becomes thinner and wrinkled. With the decrease in physical activity and the growth hormone, a decrease in muscle mass is observed (Baral-Kulaksızoğlu et al. , 2012). Hair becomes thinner, changes in posture are seen with collagen loss, and subcutaneous fat loss is experienced (Whitbourne, 2001). As in all age groups, elderly individuals may also have to cope with many mental problems. These problems can affect the individual's feelings, thoughts and behavior, as well as family and social relations. Dementia, anxiety disorders (e.g. generalized anxiety disorder, panic attack, post-traumatic stress disorder, and agoraphobia), affective disorders (e.g. major depression and bipolar disorder) and substance abuse (abuse of alcohol or prescription drugs and minor sedatives), personality disorders, and somatoform disorders are common problems in old age. Although schizophrenia, delusional disorders, and paranoia are among the rarest psychotic disorders, sleep and adjustment problems are among other mental health problems affecting the elderly (Baran-Kulaksızoğlu et al., 2012; Gridley, et al., 2000).

The concept of ageism, which means creating prejudices and negative stereotypes about the elderly, is important in understanding the aging process. Depriving the elderly from employment because they are thought to be unable to learn and cannot change easily, and isolating them from social relations because they are seen as boring and demented, and thought to have childish behaviors, are among the consequences of ageism (Rybash et al., 1991). According to Butler (1989), ageism is the most brutal form of discrimination and rejection after racism and gender discrimination. Ageism is an attitude that affects the 
preferences, competencies, weaknesses, reactions and personalities of older people. This attitude tends to stereotype them all, putting all the elderly in a stereotypical mold. Despite all these homogenizing efforts, most elderly individuals still feel fit and well. However, sometimes the elderly can be firm advocates of ageism (Gridley et al., 2000).

Body form is one of the areas where women elders are exposed to old age the most. Women who suffer from deformation in old age resort to plastic surgery on their bodies in order to conform to social aesthetic norms (Gürsu, 2005). Gürler (2018) argues that this is related to the concept of successful aging, but considering the psychospiritual nature of successful aging, it is believed that successful aging with an emphasis on physical appearance will not be possible.

Since it is seen that elderly women go through the aging process differently than men, there is a need for in-depth evaluations of the elderly in terms of psychological, sociological and physiological aspects. In order for older women to have a more successful aging process, holistic support should be provided and this support should be strengthened both institutionally and politically.

Anahtar kelimeler: Başarılı Yaşlanma, Kadın, Kentleşme, Dul Kalma, Toplumsal Sorunlar, Yaşçılık

Keywords: Successful Aging, Women, Urbanization, Widowhood, Social Problems, Ageism

\section{Giriş}

Yaşlanma temelde biyolojik değişimlerle açıklansa da insan söz konusu olduğunda toplumsal, psikolojik ve ekonomik faktörler de bu sürecin tanımlanmasında dikkate alınır. Genel olarak yaşlılık, bireyin zamana bağlı olarak iç ve dış faktörler arasında yeni dengeler kurması gereken bir süreçtir. Yaşlanma psikososyal açıdan kişiden kişiye değişmekle birlikte olumlu ve olumsuz değişiklikleri içermektedir. Dünya Sağlık Örgütü (World Health Organization) (2018) yaşlı sınıflamasını $45-59$ yas, arası orta yaş,l, $60-70$ yas, arası yaşlı, 75 - 89 yas, arası ileri yasslı, 90 yas, ve üzeri ihtiyar, 80 yaş ve üzeri ileri yaşlı, 100 ve üzeri asırlık, 110 yaş ve üzeri süper-asırlık şeklinde yapmaktadır.

Türkiye İstatistik Kurumu'nun (TÜİK) 2019 verileri incelendiğinde, Türkiye'de 2014 senesinde sayıları 6.192.962 olan yaşlı 
nüfusun beş yıl içinde \%21,9 artışla 2019 yılında 7.550.727'ye yükseldiği bilgisine ulaşılmaktadır. Yaşlı nüfusun toplam nüfus içindeki oranının da \%8'den \%9,1'e yükseldiği görülmektedir (TÜİK, 2020). Yaşlı nüfusun ve yaşlılık döneminde geçirilen sürenin artması, başarılı yaşlanmanın önemini de arttırmaktadır.

TÜİK'in (2020) verilerine göre 2019 yllında yaşlı nüfusun $\% 44,2$ 'sini erkek nüfus, \%55,8'ini kadın nüfus oluşturmaktadır. Türkiye'de doğumda beklenen yaşam süresi de giderek artmaktadır. Bugün Türkiye'de doğumda beklenen yaşam süresi ortalama 78,3 yıldır. Bu değer erkekler için 75,6 yıl ve kadınlar için 81,0 yıl şeklinde ortaya çıkmaktadır. Genel olarak kadınlar erkeklerden daha uzun süre yaşamakta olup, doğumda beklenen yaşam süresi farkı 5,4 yıl şeklinde hesaplanmaktadır. Bu açıdan bakıldığında başarılı yaşlanma kavramı kadınlar için ayrı bir hususiyet göstermektedir. Bu çalışma, cinsiyete göre yaşlanma ve başarılı yaşlanma süreçlerinin çeşitli etmenler çerçevesinde farklılaştığını dikkate alarak derinlemesine bilgi sunmak ve yaşlanan kadınların daha başarılı bir yaşlılık geçirmeleri için önerilerde bulunmak amacıyla kaleme alınmıştır. Aşağıda, başarılı yaşlanma ile kadın ilişkisine değinilerek başarılı yaşlanmanın kadınlar açısından kentleşme ve değişen aile yapısı, dul kalma ve yas, fizyolojik değişiklikler, psikolojik sorunlar, toplumsal ilişkiler, emeklilik ve yaşçılık kavramları çerçevesinde nasıl değişebildiği ortaya koyulmuş ve çeşitli değerlendirmeler gerçekleştirilmiştir.

\section{Başarılı Yaşlanma}

Geliştirilmesinin üzerinden 30 yıldan fazla zaman geçmesine karşın günümüzde hâlâ en çok atıf alan başarılı yaşlanma modeli Rowe ve Kahn'in modelidir. Rowe ve Kahn tarafindan ortaya konan bu başarılı yaşlanma modeli bugün pek çok araştırmaya temel oluşturmaktadır. Rowe ve Kahn tarafından 1987 yılında kaleme alınmış olan "Human Aging: Usual and Successful" başlıklı makalenin yayınlanmasından sonra "aktif yaşlanma", "pozitif yaşlanma", 
"sağlıklı yaşlanma” ve "ideal yaşlanma" gibi kavramlarla literatürün genişlediği; bu makalenin sadece geriatri, gerontoloji veya yaşlanma literatüründen değil; hemşirelik, diş bilimi, psikoloji, sosyoloji, siyasal bilimler ve yaşlanmayla ilgili medikal, sosyal, kültürel ve siyasal tüm alanlardan da atıf aldığı görülmektedir (Bülow \& Söderqvist, 2014). Rowe ve Kahn'a (1997) göre birbiriyle ilişki ve belli bir hiyerarşi gösteren üç temel yapı taşından (hastalık ve hastalığa bağlı engel olasılığının düşük olması, yüksek bilişsel ve fiziksel işlev kapasitesi ile aktif yaşam biçimi) meydana gelen başarılı yaşlanma; "bireyin fiziksel, ruhsal ve toplumsal olarak uyum halinde olması" şeklinde tanımlanmaktadır.

Başarılı yaşlanma tanımının üç temel yapıtaşından biri olan düşük hastalık olasılığı sadece hastalık riskinin varlığı yahut yokluğunu değil; var olan riskin ciddiyetini de kapsamaktadır. Yüksek işlevsel kapasite, fiziksel ve bilişsel yapıtaşlarını içermekle birlikte; fiziksel ve bilişsel kapasiteler bireyin ne kadar aktif olabileceğinin potansiyel göstergesi olarak ele alınmaktadır. Başarılı yaşlanmayla ilişkilendirilen bir diğer değişken ise aktif yaşam tarzıdır. Aktif yaşam tarzı kavramı, pek çok şekilde tanımlanmakla birlikte daha çok kişiler arası ilişkiler ve verimli aktivitelerin üzerinde durulmaktadır. Burada ele alınan kişiler arası ilişkiler kavramı diğer insanlarla kurulan etkileşimler, duygusal destek ve direk yardım kavramlarından meydana gelmektedir (Rowe \& Kahn, 1997).

Rowe ve Kahn, seneler içinde başarılı yaşlanmaya ilişkin gerçekleştirdikleri araştırmalar sonucunda ilgili değişkenleri farklı biçimlerde ele almıştır. 1996 yılında ortaya konan modele göre başarılı yaşlanmaya ilişkin değişkenler bilişsel ve fiziksel işlev, yaşam aktivitesinin sürdürülmesi (sosyal ilişkiler, sosyal destek), üretici faaliyetler (işlevsel kapasite, eğitim ve özyeterlilik) şeklinde ele alınırken, 2004 yılında bu değişkenler Kahn tarafından genel sağlık algısı, medikal risk faktörleri (kan basıncı, şeker, kolesterol, kilo vb.), yaşamdaki risk faktörleri (sigara içme, 
emniyet kemeri takma, alkol tüketimi vb.) başlıkları altında sıralanmaktadır.

Başarılı yaşlanmaya ilişkin literatür incelendiğinde kavrama ilişkin tek bir sınırlı tanımlamanın yer almadığı, kavramın tanımlanmasında pek çok farklı bileşenin ele alındığı görülmektedir (Ebner ve Freund, 2007). Prudential'a (2015) göre başarılı yaşlanma tamamen tutumla ilgilidir: Birey iyimser olduğu, hayatı sonuna dek yaşadığı, potansiyelini tamamıyla kullandığı, yaşlılığı kendi şartlarına göre yönettiği ve ayrıca hayatta karşısına ne çıkarsa çıksın kabulle karşıladığı sürece başarılı yaşlanmaktadır.

Bowling ve Dieppe (2005) tarafından başarılı yaşlanmanın tanımına ilişkin gerçekleştirilen genel derlemede başarılı yaşlanmanın temel teorik bileşenleri doğumda beklenen yaşam süresi, yaşam doyumu ve iyi oluş, zihinsel ve ruhsal sağlık, bilişsel işlevler, kişisel gelişim, yeni şeyler öğrenme, fiziksel sağlık ve işlevler, bağımsız yaşam, algılanan özerklik, kontrol, bağımsızlık, uyum, başa çıkma, özsaygı, olumlu bakış açısı, hedefler, benlik algısı gibi psikolojik özellikler ve kaynaklar, sosyal katılım, boş zaman aktiviteleri, sosyal bağlantılar, destek, katılım, fiziksel aktivite şeklinde sıralanmaktadır. Bu temel teorik bileşenlere ek olarak başarılar, beslenmeden keyif alma, ekonomik güvenlik, komşuluk, fiziksel görünüş, üretkenlik ve yaşama katkı, mizah duygusu, amaç duygusu ve maneviyat gibi alt tanımlar da eklenmektedir.

Başarılı yaşlanma üzerine kurgulanan modellerden bir diğeri başarılı bilişsel yaşlanma modelidir. Başarılı bilişsel yaşlanma modeline göre başarılı bilişsel yaşlanma; çoklu bilişsel yapılar, hafıza ve yürütücü işlevler gibi geleneksel nöropsikolojik becerilerden ziyade bilgelik ve psikolojik dayanıklılık gibi daha ötesini ele almayı kapsamaktadır. Başarılı bilişsel yaşlanmanın temel göstergeleri incelendiğinde ise genetik etkenler, stres ve psikolojik dayanıklılık, beyin hacmi ve bilişsel hacim, bilgelik ve yaşam tarzı davranışları (fiziksel aktiviteler, beslenme alışkanlıkları, bilişsel uyarımlar) ile karşılaşılmaktadır (Depp vd., 2012). 


\section{Başarılı Yaşlanma ve Kadın}

Kadınların erkeklerle farklı psikolojik ve fizyolojik özellikler gösteriyor olmaları yaşlanma deneyimlerini de etkilemektedir (Gökçe Kutsal ve Bal, t.y.). Bu özellikler kadınların yaşlılıktaki fizyolojik sağlık, aile yaşamı, toplumsal ilişkiler, üretim ve emeklilik, yaşçılık gibi ögeler açısından farklı deneyimler geçirmesine neden olmaktadir.

Cinsiyet farklılıklarının ve eşitsizliklerin eğitim ve istihdam olanaklarındaki etkisi, bireysel yaşantının her aşamasında görülmekte, yaşlılıkta ise zirveye ulaşmaktadır. Daha az eğitim alan ve istihdama daha az katılan yaşlı kadınların yaşlı erkeklerden daha düşük gelir düzeyine sahip olma olasılığı da daha yüksek olmaktadır. Erkekler ve kadınlar, yaşlandıkça, farklı sağlık problemleri yaşamakta ve maddi imkânsızlıklar dolayısıyla kadınların yeterli bakıma erişemedikleri görülmektedir (United Nations Division for the Advancement of Women Department of Economic and Social Affairs, 2002).

Park, Jang ve Kim (2009) tarafindan Kore'de başarılı yaşlanmanın cinsiyet değişkenine göre farklılaşması üzerinde gerçekleştirilen araştırmada sosyoekonomik düzeyin kadın ve erkek yaşlıların fiziksel ve sosyal işlevselliği üzerinde etkisi olduğu bulgulanmıştır. Özellikle yüksek gelire sahip olan erkek yaşlıların yüksek fiziksel işleve de sahip olduğuna dikkat çekilmiştir. Kadınlarda ise eğitimin fiziksel işlevsellikle yüksek düzeyde ilişkili olduğu görülmüştür.

Thielke ve Diehr (2012) tarafindan yaşlıların başarılı yaşlanma durumlarına ilişkin on iki ölçümün gerçekleştirildiği araştırmada, yıllar geçtikçe sağllğın bozulduğu fakat bu bozulmanın her iki cinsiyette benzer sonuçlar verdiği görülmüştür. Kadınlar ve erkeklerin yaşlanma sürecinde sağlık açısından farklılıklara da rastlanmıştır. Bu süreçte erkekler daha az hastalık belirtisi gösterirken daha erken öldükleri tespit edilmiştir. Türkiye'de de erkeklerin doğumda beklenen yaşam süresi kadınlara nazaran daha kısadır (TÜİK, 2020). Bunun kadınların sağlığa bakış açılarından, tedaviye 
yaklaşımlarından ya da temel biyolojik yapılardan kaynaklandığı düşünülmektedir. Nosraty, Sarkeala, Hervonen ve Jylha (2012) tarafindan Finlandiya'da doksan yaş ve üstündeki yaşlıların başarılı yaşlanma durumlarının incelendiği araştırmada da erkek katılımcıların kadın katılımcılara nazaran daha başarılı yaşlandıkları görülmektedir. Garcia ve arkadaşları (2011) tarafindan Madrid'de gerçekleştirilen ve başarılı yaşlanmanın yordayıcılarının incelendiği bir araştırmada cinsiyet, başarılı yaşlanmayı yordayan en önemli demografik değişken olarak belirlenmiştir.

Literatür incelendiğinde, erkek yaşlıların kadınlara nazaran daha iyi yaşlandığı bulgusunun daha ağırlıkta olduğu görülmektedir (Garcia vd., 2011; Maccora vd., 2018; Nosraty vd., 2012; United Nations Division for the Advancement of Women Department of Economic and Social Affairs, 2002). Erkeklerin lehine gerçekleşen bu farklılığın temelde sosyoekonomik farklılıklar dolayısıyla kadınların gerekli hizmetlere ulaşmakta güçlük yaşamaları dolayısıyla oluştuğu düşünülmektedir (Park vd., 2009; United Nations Division for the Advancement of Women Department of Economic and Social Affairs, 2002). Thielke ve Diehr (2012) ise yaşlanma sürecinde çeşitli hastalıkların oluştuğunu fakat yaşlılığa bağlı bu değişimlerin her iki cinsiyette de görüldüğünü ortaya koymaktadır. Hsu (2005) tarafindan çeşitli değişkenler açısından cinsiyetler arası farklılıkların incelendiği bir başka araştırmada kadın ve erkeklerin farklı alanlarda avantaj ve dezavantajlara sahip olduğu dikkat çekmektedir. Araştırmada yaşlı kadınların günlük yaşam aktivitelerinde daha iyi performans gösterdiğini ve enstrümental yaşam aktivitelerinde (başkalarına bakım verme, iletişim becerileri, sağlık yönetimi vb.) ise daha az kırılgan olduğu bulgulanmaktadır. Kadınların genel dezavantajlarının ise daha çok sağlıktaki bozulmalarla ilişkili olduğu sonucuna ulaşılmaktadır.

\section{Kadınların Başarılı Yaşlanmasını Etkileyen Faktörler}

Kadınlar, gençlik yıllarında olduğu gibi yaşlılıklarında da toplumsal cinsiyet ve cinsiyet özellikleri açısından farklı deneyimler 
geçirmektedir (Özçakır, 2016). Aşağıda kadınların yaşlılık sürecini etkileyen faktörler başarılı yaşlanma perspektifinden ele alınmaktadir.

Kentleşme ve değişen aile yapısı: Sanayileşmenin hızla artmasıyla birlikte kent nüfusu da çok hızlı bir biçimde artmıştır. Kentlere gerçekleşen bu gö̧̧lerin temel sebebi ise iş bulma kaygısıdır. İlk kentleşme dalgasında kadınlar ev içi hayata daha çok yönlendirilmiş olmakla birlikte özellikle İkinci Dünya Savaşı'nın ardından kadınlar da dışarıda çalışma hayatına büyük ölçüde katılmaya başlamıştır. Kadının dışarıdaki çalışma hayatında yer alması kadını sosyoekonomik açıdan güçlendirmiş, hizmetlere erişimini kolaylaştırmış, erkek ve kadın cinsiyeti arasındaki toplumsal cinsiyet rolleri farklılığını azaltmıştır (Buz, 2009; İnce-Güney, 2014). Bununla birlikte kadının çalışma hayatındaki etkinliğinin halen erkeklere oranla çok daha geride olduğu dikkat çekmektedir. Kadınlar çalışma hayatına katılsalar dahi ev işlerinin sorumluluğunun kendilerinden beklenmesi dolayısıyla toplumsal cinsiyet rolleri açısından eşitsizlik devam etmekte; kadınların çalışma ortamlarında da değişiklikler yapılmaya ihtiyaç duyulmaktadır (Tarhan, 2020).

Modernleşmeyle birlikte insanların yaşam biçimlerinde ve coğrafi yerleşimlerde hızlı bir değişim görülmeye başlamıştır. Köylerden kente hızlı bir göç başlamış ve kontrol edilemeyen bu insan akışı dolayısıyla kentler daha karmaşık yerler haline dönüşmüştür (Yörükan ve Yörükan, 2005). Sanayileşmenin etkisiyle kırsaldan kente göçen gençlerin ebeveynleri kentte yaşlanmış ya da kente yerleşen çocuklarının yanında yaşamına devam etmek zorunda kalmıştır. Bu durum yaşlının bu yeni karmaşık dünyaya uyumunu güçleştirmiş, bu da pek çok soruna yol açmıştır. Yoğun iş yaşamı çocuklarının yaşlı ebeveynleriyle olan bağlantısını zayıflatmıştır. Daha fazla olanağa sahip olması dolayısıyla kendisinden daha eğitimli ve daha yüksek statüde çocukları olan yaşlılar kırsaldaki aile içi prestijini kaybetmiştir (Köroğlu ve Köroğlu, 2015). Türkiye'de eğitim durumu açısından yaşlılar incelendiğinde, kadınların belirgin bir şekilde erkeklerden çok daha düşük eğitim düzeyine sahip 
olduğu dikkat çekmektedir (TÜİK, 2020). Bu açıdan yaşlı kadınların ev içerisindeki prestij kaybı ve diğer uyumlanma sorunları açısindan daha dezavantajlı olabileceği düşünülmektedir.

Sağlık teknolojisinin gelişmesiyle yaşlılar bağımsız bir yaşam sürdürebiliyor, desteğe ihtiyaç duymuyor olsa da çocuklarıyla ve torunlarıyla vakit geçirme istekleri devam etmektedir (Billig, 2000). Ancak ailelerin küçülmesi, anne babaların her ikisinin de çalışma hayatında yer alması, evde geçirilen zamanlarda diğer ihtiyaçlar ve çocukların ihtiyaçlarına zaman ayrılması dolayısıyla büyükanne ve büyükbabaların çocuk ve torunlarıyla geçirebilecekleri zamanlar da kısıtlanmaktadır. Schmid'e (2018) göre modern yaşam dolayısıyla büyükanne ve büyükbabalar geçmişe göre torunlarıyla daha nadir bir araya gelse de birlikte olduklarında verimli zaman geçirmeye devam etmektedir. Torunlarla büyükanne büyükbaba arasındaki ilişkinin anne baba çocuk ilişkisinden farklı olarak her iki tarafın da isteğiyle özgür bir biçimde tercih ediliyor olmasının ilişkideki bağı kuvvetlendirdiği öne sürülmüştür. Ayrıca ebeveynlerin günlük yaşamın stresinin de etkisiyle oluşan aşırı kuralcı düzeninin dışında büyükanne ve büyükbabalar günlük yaşam stresinden uzaklaşmış olmanın artısıyla torunlarına daha özgür bir alan inşa edebilmektedir. Bu da aralarındaki doyumu arttırmaktadır.

Dedelik/ ninelik yaşlı bireyler tarafından istenen bir şey olmakla birlikte (Demir-Çelebi ve Yüksel, 2018; Uğur, 2018) kendi torununa bakıcılık yapmanın bazı uyum sorunlarına da yol açtığı görülmektedir. Kendi torunlarına bakım veren yaşlılarla gerçekleştirilen bir araştırmada, bakım vermenin yoğunluğu dolayısıyla büyükanne ve büyükbabaların sosyal yaşamdan izole olduğu, bakım sürecinde destek almakta güçlükler yaşadığı görülmektedir. Torun bakmanın olumlu yönlerini ifade ederken yaşlı kadınların zorluklara da vurgu yaptığı, sürecin kendileri için zorlayıcı olduğuna dair ifadelerde bulundukları dikkat çekmektedir (Taşkın ve Akçay, 2019). Yaşlıların torunlarına bakım verme hususunda çocuklarıyla anlaşmazlıklar yaşayabildiği ve bu sorumluluk dolayısıyla aralarında çatışmaların 
doğabildiği de araştırma bulguları arasında yer almaktadır (Yüksel ve Demir-Çelebi, 2019).

Dul kalma ve yas: Dul kalma, yaşamdaki en stres verici olaylar arasında sayılmaktadır (Silverstein ve Giarrusso, 2010). Yıllarca evli olan yaşlı yetişkinler için, evlenmeden önceki yaşamı hatırlamak zordur. Eşinin ölümünden sonra yeni bir hayat kurmak ise daha zorlayıcıdır. Eşin yasını tutmak yaşlı bireyin kendi ölümlülügünü hatırlaması, yalnız kalması ve bu yaşlarda üst üste ölümle yüzleşmesi açısından da yaşlıyı zorlayabilmektedir. Sosyal desteğin bu dönemde bu denli önemli olmasının temel belirleyicilerindendir (Stambuck, 2019). Türkiye'deki yaşlılık istatistikleri incelendiğinde dul kadın yaşlıların oranının dul erkek yaşlıların oranının dört katı olduğu tespit edilmiştir (TÜİ, 2020). Kadınların erkeklere nazaran daha uzun ömürlü olmaları dolayısıyla ileriki yaşlarını dul olarak geçirme riskleri daha yüksektir.

Bazen bir eşin (özellikle bir bakıcının) ölümü, hayatta kalan eşin bakımevine taşınması ve böylece kaybın iki kez yaşanması anlamı taşımaktadır. Bu gibi durumlarda hızlı bir şekilde normal yaşama dönme beklentisi hem bakım personeli hem de birey için zararlı sonuçlar doğurabilmektedir (Gridley vd., 2000).

Dulluğun olumlu yanları da bulunmaktadır. Bazı yaşlılar için dulluk yeni bir hayata başlamak için bir firsat sağlamakta ve bu kişilerin öz-yeterlilik duyguları artabilmektedir (Arbuckle ve de Vries, 1995). Özellikle eşin kaybıyla birlikte erkeğin arkadaş çevresi daralırken, kadınınkinin daha fazla genişlediği görülmektedir. Bunun da, kadının daha önceki görev ve sorumluluklarından dolayı arkadaşlarına ayıramadığı vakti bu dönemde kolaylıkla ayırmasından kaynaklandığı düşünülmektedir (Rybash vd., 1991). Yaşlı kadınların sosyal ilişkileri yas sürecini sağlıklı bir biçimde geçirmelerini kolaylaştırmaktadır. Efe ve Aydemir (2015) tarafindan huzurevinde yaşayan yaşlı kadınların deneyimlerinin incelendiği bir araştırmada kadınların eşlerinin vefatının ardından birbirlerine yoldaş olduklarını ifade ettikleri görülmektedir. 
Literatür yaşlıların, eşleri, arkadaşları ve diğer aile üyeleri de dâhil olmak üzere sevdikleri pek çok kimsenin ölümüne şahit olduklarını ortaya koymaktadır (Shear vd., 2013). Yasın etkileri ölümün gerçekleştiği ilk zamanlarda daha yoğun görülürken zaman geçtikçe yaşlıların iyi oluşlarının yükseldiği görülmektedir (Luhmann vd., 2012). Yas, başa çıkılması zor bir durum olmakla birlikte sosyal yaşamda daha aktif olan yaşlıların çoğunlukla dul oldukları görülmektedir. Hastalıklar dolayısıyla eşine bakım verme durumunda kalan yaşlılar eşlerinin vefatından evvel sosyal yaşama katılamadığı, eşin vefatından sonra akraba ve arkadaş desteğinden dolayı da sosyal katılımın arttığı düşünülmektedir (Utz vd., 2002). Ancak yaşamın büyük bir çoğunluğunun birlikte geçirildiği eşin vefatıyla yaşlı bireyin senelerce sürdürdüğü yaşam biçimi ve alışkanlıkları değişmekte; yasın getirdiği hüzne uyum sorunları da eklenebilmektedir.

Fizyolojik değişiklikler: Yaşlanmayla birlikte deri daha çok kurumaya, incelmeye ve kırışı bir hal almaya başlamaktadır. Büyüme hormonu ile fiziksel aktivitenin azalmasıyla kas kütlesinde de azalma görülmektedir (Baral-Kulaksızoğlu vd., 2012). Saçlar seyrelmekte, kolajen kaybıyla birlikte postürde değişmeler görülmekte ve deri altı yağ kaybı yaşanmaktadır (Whitbourne, 2001).

Yaşlanmayla birlikte gerçekleşen yaşa bağlı bozulmalardan biri de osteoporozdur. Osteoporoz, kemik kütlesinde azalma ve kemik dokusunun mikro-mimarisinde bozulma sonucunda kemik kırılabilirlik eğiliminin artması şeklinde açıklanan metabolik bir hastalıktır (Cosman vd., 2014). Seksen beş yaşından sonra sık görülen osteoporoz genellikle kemik kırılmalarından sonra fark edilmektedir.

Cinsellik, partnerler arasındaki yakınlaşmaya destek sunan bir olgudur. Yaşlılıkta cinsel yaşamı etkileyen değişiklikler gerçekleşmektedir. İlerleyen yaşla birlikte insan vücudunda yaşanan değişiklikler bireyin cinsel yaşamını da etkilemektedir. Cinsel Eğitim Tedavi ve Araştırma Derneği (2006) tarafindan hazırlanan raporda 
Türkiye'de en çok yaşlı ve bekar kadınların cinsel işlev bozuklukları yaşadığı bilgisine ulaşılmaktadır. Yaşlı kadınlarda östrojen ve progesteron hormonlarının azalması dolayısıyla görülen vajinal kas kaybı, ağrılı cinsel ilişki, cinsel ilişki esnasında kanama, meme bezlerinde kas kaybı görülebilmektedir (Ginsberg vd., 2005; Mroczek vd., 2013; Özkayar ve Arığul, 2007; Yıldırım vd., 2012). Bu dönemde uyarılma hem kadın hem erkek için geç gelişmekte, orgazm gençlik yıllarına göre daha kısa süreli ve yumuşak belirmektedir. Ancak cinsel birleşme hastalık, hastanede yatma ve tüm diğer fizyolojik engellere rağmen gelişemese bile yaşlıların yakınlık, dokunma, duygusal yakınlaşma, şehvet gibi diğer cinsel ihtiyaçları devam etmektedir (Rybash vd., 1991).

Yaşlanan birey fiziksel sağlık sorunlarının yanı sıra mental sağlık sorunlarıyla da karşılaşmaktadır. Bellekte basit bozulmalar, demans ve demansın bir alt türü olan ancak en fazla tanı alan Alzheimer yaşlı bireyin maruz kaldığı mental sağlık sorunları arasında yer almaktadır (Demir-Çelebi, 2019). Normal gelişen bir yaşlılıkta bilişsel gelişimde gözlenen olumsuz değişimler bireyin yaşamını etkileyecek düzeyde değildir. Bununla birlikte, görülen bilişsel bozulmalar hafif bilişsel bozukluklardan ileri demansa kadar genişleyen bir yelpazede seyretmektedir. Hafizada görülen basit yavaşlamalar yaşa bağlı bilişsel değişimler açısından normal kabul edilmektedir. Ancak ilerleyen mental hastalıklar ciddi birer halk sağlığı sorunu olarak görülmektedir. Bu mental sorunlar duygusal ve sosyal problemleri de beraberinde getirmekte; sağlıkta bozulmalara, sakatlanmaların, ölüm riskinin artmasına, tıbbi hizmetlere daha çok ihtiyaç duyulmasına ve tedavi uyumunun azalmasına zemin oluşturmaktadır (Karlin ve Fuller, 2007). Bu açıdan sağlıklı bilişsel yaşlanmanın kapsamını ve süreçlerini incelemek, yaşamı iyileştirme modelleri geliştirme ve demans gibi patolojik süreçlerde neler olduğunu anlama açısından büyük öneme sahiptir (Gridley vd., 2000).

Psikolojik sorunlar: Tüm yaş gruplarında olduğu gibi yaşlı bireyler de pek çok ruhsal problemle baş etmek durumunda kalabilmektedir. Bu sorunlar bireyin duygu, düşünce ve davranışlarıyla aile 
ve sosyal ilişkilerini etkileyebilmektedir. Demans, kaygı bozuklukları (örn. yaygın anksiyete bozukluğu, panik atak, post travmatik stres bozukluğu ve agorafobi), duygulanım bozuklukları (örn. majör depresyon ve bipolar bozukluk) ve madde kullanımı (alkol veya reçeteyle satılan ilaçlarla küçük sakinleştiricilerin kötüye kullanımı), kişilik bozuklukları, somatoform bozukluklar gibi problemler yaşlılıkta görülen yaygın sorunlardandır. Şizofreni, sanrı bozuklukları ve paranoia en nadir görülen psikotik bozukluklardan olmakla birlikte uyku ve uyum problemleri yaşlıyı etkileyen diğer ruh sağlığı problemleri arasında sayılmaktadır (Baran-Kulaksızoğlu vd., 2012; Gridley vd., 2000).

Depresyon, yaşlılıkta oldukça nadir görülse de birey ilk depresyon deneyimini bu dönemde yaşayabilmektedir. İleri yaşlarda yaşanan fiziksel görünümde değişiklikler, güç kaybı, toplumsal rollerde değişim ve prestij kaybı ile fiziksel ve mental yetersizlikler yaşanmakta, bu yetersizlikler arttıkça yaşlı birey bağımlı hale gelmektedir. Bağımlılıkla birlikte üzüntü, suçluluk, karamsarlık, mutsuzluk gibi duygularla karakterize depresif bozukluklar gelişebilmektedir (Aksüllü, 2001; Ançel, 2007; Duru ve Özdemir, 2009). Depresyon, çok yakın bir arkadaşın kaybı gibi bazı stresli yaşam olayları sonucunda ortaya çıkabildiği gibi kesin bir neden olmadan da görülebilmektedir. Bazı bireyler yaşamları boyunca depresyona eğilimli olabilmekte, bu yaşlılıkta da devam edebilmektedir (Gridley vd., 2000).

Yaşlılar gençlik yıllarına göre daha az alkol tüketmesine karşın alkolle ilgili yaşanan sıkıntılar devam edebilmektedir (Hanson \& Gutheil, 2004). Yaşlllık yıllarında alkol tüketim oranı azalsa da vücudun daha az alkole daha yüksek tepki vermesi ve yaşlı bireyin alkol alımı hususunda kendini sınırlayamaması gibi hususlar alkolle ilgili problemlerin artmasına neden olabilmektedir. Kadın yaşlıların alkol bağımlılığı hususunda erkeklere nazaran daha az risk taşıdığ bilinmekle birlikte, reçeteli ilaçlara ilişkin bağımlılık konusundan risk taşıdıkları da görülmektedir (Çavuşoğlu ve Demirkol, 2018).

Türkiye'de yaşlı intiharları gençlere nazaran daha az sıklıkla görülse de yaşlılıkta intihar oranlarının giderek arttığı dikkat 
çekmektedir. Yaşlılıkta intihar nedenleri arasında duyu kaybına neden olan kronik hastalıklar (kalp hastalıkları, nörolojik hastalıklar, kanser vb.), yalnızlık, depresyon, alkol veya ilacı kötüye kullanım, geçim sıkıntısı ve kimyasal bağımlılıklar yer almaktadır (Duru ve Özdemir, 2009). Yaşlılıtta intihara sebep olan nedenlerden biri de kronik ağrılardır. Somatik kronik ağrıların psikolojik terapiler yardımıyla giderilmesi intihar riskini düşürmektedir. Ancak pek çok insan ağrının teşhisi sırasında fazla zaman kaybettiği ve ağrının somatik durumu fark edilmediği için senelerce acı çekmek zorunda kalmaktadır. Çok yönlü ağrı tedavi yaklaşımlarının yanı sıra somatik rahatsızlıklarda hipnoz, psikoterapi, destekleyici psikolojik danışma ve grup terapileri de kullanılmaktadır (Gridley vd., 2000).

Erikson'a (1984) göre yaşlılık döneminin temel çatışması bütünlüğe karşı umutsuzluktur. İnsanlar bu dönemde yaşamın sonuna geldiğini düşünerek tüm yaşamlarını ve kendilerini nasıl hissettiklerini gözden geçirmektedir: "Yaşamın zorluklarını başarılı bir şekilde karşılamış mıyım / önem verdiğim hedeflerime ulaşabilmiş miyim / sevdiklerimin refahına katkıda bulunmuş muyum? Yoksa potansiyelimi anlamakta geç mi kalmışım / zamanımı gereksiz işler ve anlamsız ilişkilere mi harcamışım / başkalarına yük mü oluyorum?” Bu sorulara çoğunlukla olumlu yönde cevap veren yetişkinlerin daha müstağni bir yaşlılık geçirdiği ileri sürülmektedir (Hewstone vd., 2005).

Toplumsal ilişkiler: Montross ve arkadaşları (2006) tarafından yaşlıların başarılı yaşlanma durumu üzerine gerçekleştirilen bir araştırmada başarılı yaşlanma ile arkadaş sayısı ve aileyi ziyaret sıklığı arasında anlamlı bir ilişki bulunmuştur. University of California'da 2003-2013 yılları arasında doksan yaş ve üzeri 950 bireyden başarılı yaşlanma verileri toplayan sinirbilimci Kawas ve arkadaşlarına göre sosyal ilişkiler ile başarılı yaşlanma arasında sıkı bir ilişki bulunmaktadır (NRTA: AARP's Educator Community, 2009). Yaşlı bireylerin başarılı yaşlanma algılarına yönelik gerçekleştirilen araştırmada da gerçekçi öz değerlendirme, yaşamı gözden geçirme ve ana odaklanma gibi alt başlıkları içeren öz kabul/ öz sevi 
bileşeni ile yeni uğraşlar, başkalarına yardım, sosyal ilişkiler ve pozitif tutum alt başlıklarını içeren aktif yaşam/ öz gelişim bileşenlerinin başarılı yaşlanmanın tanımının temel anahtarları olduğu ortaya konmuştur (Reichstadt vd., 2010).

Diğer insanlarla birlikte olmanın ötesinde çoğu insan başkalarıyla sıcak ve yakın bir ilişki kurma ihtiyacı duymaktadır. Biri, duygusal bağlanmayı ifade eden romantik bir ilişki; diğeri ise arkadaşlarla bir bağ kurmayı içeren arkadaşlık ilişkisi olmak üzere yetişkinler iki tür ilişki arayışında olmaktadır. Bu iki ilişki biçimi farklı ihtiyaçlara hizmet etmektedir. Birincisi refah ve güvenlik sağlarken, ikincisi gruba aidiyet ve uyum duygusunun oluşmasına yardımcı olmaktadır (Rybash vd., 1991). Bununla birlikte ileri yetişkinlikte arkadaşlık ilişkilerinin rehberlik etme, başkaları için sorumluluk alma, bağlanma, değerli hissetme ve yalnız hissetmeme gibi kazançları da bulunmaktadır (Slater, 1995).

Genç yetişkinlikte özellikle yeni evli bireylerin birçok arkadaşlık ilişkisi kurduğu bilinirken bu bağların yaşlandıkça zayıfladığı görülmektedir. Yaşlı bireyler çocukların evden ayrılması, arkadaş ve eşlerin ölümü ve fiziksel aktivitenin kısıtlanmasıyla birlikte daha az sosyal temas kurarak yalnız kalmaktadır. Bununla birlikte, insan yaşamının tüm dönemlerinde olduğu gibi yaşlılıkta da güvenli ve yakın ilişkiler kurmak önemli olduğu için bu dönemde özellikle yaşlıların yakınlarının destek sunması bu bireylerin yaşam doyumlarına olumlu katkı sunabilmektedir (Baral-Kulaksızoğlu vd., 2012; Rybash vd., 1991).

Emeklilik: Emekliliğin anlamı son nesilde değişmiştir. Bugünkü anlamıla emeklilik, üretkenliğin bittiği anlamına gelmek yerine yeni bir deneyim sayfasının açıldığını gösteren bir nitelik sunmaktadır. Emeklilik yaşlılar için her zaman zorluk anlamına gelmemektedir. Başarılı emeklilik için bireyin tercih edilen zamanda emekli olması, finansal olarak kendine yetmesi ve bir bütün olarak yaşamdan memnun olması beklenmektedir. Sharpley ve Layton (1998) emekliliğe duygusal ve sosyal olarak hazırlıklı olmanın başarılı uyumu öngördüğünü, istemsiz emekliliğin düşük uyumlanma 
açısından güçlü bir risk faktörü olduğunu ifade etmektedir. Bununla birlikte, Avustralya'da emekli erkeklerin sadece \% 37'si ve emekli kadınların \% 22'si emekliliğe aktif olarak hazır olduklarını belirtmektedir (Wolcott, 1998) ve emekli erkeklerin \% 20'si ve emekli kadınların \% 11'i kendilerini emekli olmak zorunda hissettiklerini ifade etmektedir (Sharpley vd., 1996).

Yaşla ilgili tutumlar, birçok çalışma ortamını etkilemekte ve yaşlı işçilerin yavaş, değişimle başa çıkamayan ve zorlu entelektüel görevleri yerine getiremeyen olduklarına ilişkin basmakalıp görüşlerin hâlâ etkin olduğu görülmektedir (Thomas, Browning ve Greenwood, 1995). Ancak üretkenliğin yaşla birlikte azalmadığı, yaşlı çalışanların iş yerinde yaralanma oranının daha düşük olduğu ve yaşlı çalışanların en az gençler kadar üretime katkı sunduğu bilinmektedir (Seedsman, 1996).

Bir birey yaşlandığında toplumda onun emekli olması gerektiği; çünkü yaşlı birey gözlerinin iyi görmediği, fiziksel dayanıklılıklarının olmadığı, işitmede güçlük yaşadığı ve yavaş hareket ettiği gibi kalıplara sokulmaktadır. Bireyin iş yaşamından çekilmeye yönlendirilmesi nezaketen de yapılsa yaralayıcı olabilmektedir. Bu yaş dönemindeki bireyler her ne kadar iş yaşamından ayrılmış olsa da enerjilerini harcayacakları bir alana ihtiyaç duymaktadır. Bunun için yarı zamanlı işler, hobiler, bahçe işleri, koçluk, öğretmenlik ya da mentorluk yapmak iyi birer seçenek olabilmektedir (Osborne, 2012).

Emeklilik ve emekliliğe uyum sağlama süreçleri de toplumsal cinsiyet perspektifinden bazı farklılıklar taşımaktadır. Yaşlı kadınların çocuk ve torun bakımı gibi aile fonksiyonlarının yanı sıra ev işleriyle uğraşıyor olmaları kadınların erkeklere göre emekliliğe daha çabuk uyum sağlayabilmelerine imkân tanımaktadır (İlgar, 2008). Ancak alışma yaşamında kadının konumu da kadın emekliliğini olumsuz yönde etkilemektedir. Bu bağlamda ülkemizde ve pek çok ülkede kadınların erkeklerden daha önce emekli olması onların erkeklerden daha düşük emekli maaşı ve ikramiyesi almalarına sebep olmaktadır (Terakye ve Güner, 1992). Bununla birlikte istihdama 
katılan kadın oranının erkeklere nazaran daha düşük olduğu da bilinen bir gerçekliktir (Tarhan, 2020). Bu açıdan emekliliğin bugünkü yaşlılarda büyük bir uyum sorunu yaşatmayacağı söylenebilmektedir. Efe ve Aydemir (2015) tarafından Isparta Huzurevi'nde gerçekleştirilen araştırma bulguları da kadınların yaşamlarını kırsal bölgelerde ev içi ve tarım faaliyetleriyle geçirdikleri, dolayısıyla emeklilik hususunda görece daha az zorluk yaşadıkları görülmektedir.

Yaş̧̧ılık (ageism): Yaşlılara ilişkin ön yargı ve olumsuz kalıp yargılar oluşturmak anlamına gelen yaşçılık (ageism) kavramı yaşlanma sürecinin anlaşılması bakımından önemlidir. Yaşlıların kolay öğrenemediğinin ve değişemediğinin düşünülmesi sebebiyle istihdam edilmemesi, sıkıcı ve bunamış görüldükleri için sosyal iliş̧kilerden soyutlanması, çocukça davranışlara sahip olduğunun düşünülmesi gibi durumlar yaşçlığın sonuçlarındandır (Rybash vd., 1991). Butler'a (1989) göre yaşçlık (ageism), ırkçılık ve cinsiyet ayrımcılığndan sonra en zalim ayrımcılık ve reddetme şeklidir. Yaşçılık, yaşlı insanların tercihlerini, yeterliliklerini, zayıflıklarını, tepkilerini ve kişiliklerini etkileyen bir tutumdur. Bu tutum bütün yaşlıları stereotipik bir kalıba sokarak hepsini tektipleştirme eğilimindedir. Tüm bu tektipleştirme çabalarına karşın birçok yaşlı birey kendisini hâlâ fit ve iyi hissetmektedir. Bununla birlikte bazen yaşlılar da yaşçılığın sıkı savunucularından biri olabilmektedir (Gridley vd., 2000).

Başarılı ve aktif yaşlanma kavramlarının tanımlanmasıyla ve bu konudaki çalışmaların artmasıyla toplumda bilinen klişelerin aksine yaşlı bireylerin kendilerini zinde hissettiği ve topluma katkı sunmaya devam ettiği bilgilerine ulaşılmaktadır. Yapılan araştırmalar emeklilerin kendilerinden sonraki nesle katkı sunduğunu (Greene, 1997), bakıma ihtiyaç duyanlara bakım verdiğini (Wells \& Kendig, 1997), toplum ve eğitim merkezlerinde gönüllü olarak çalıştığını (Greene, 1997; Swindell \& Vassella, 1999) ortaya koymaktadir. 
Kadın yaşlıların en fazla yaşçılığa maruz kaldıkları alanlardan biri de beden formudur. Toplumsal estetik normları dolayısıyla yaşlılıkta deformasyona uğrayan kadınlar bedenlerinde estetik cerrahi operasyonuna başvurmaktadır (Gürsu, 2005). Gürler (2018) bunun başarılı yaşlanma kavramıyla ilişkili olduğunu ortaya koymakta ancak başarılı yaşlanmanın psikospiritüel yapısı göz önünde bulundurulduğunda bedensel görüntüye önem verilen bir başarılı yaşlanmanın mümkün olmayacağına inanılmaktadır.

Arun ve Pamuk (2014) tarafından yaşlı bakım personelinin yaşçılık (ageism) tutumunu ortaya koymak üzere gerçekleştirilen araştırma sonuçlarına göre yaşlılara bakım veren personellerin bile oldukça yüksek düzeyde yaşçılık (ageism) tutumuna sahip olduğunu ortaya koymaktadır. Bakım personelinin yaşlılara profesyonel biçimde yaklaşması gerektiği, bu alanda bilgi ve tecrübe sahibi olduğu göz önünde bulundurulduğunda yaşçılık (ageism) tutumuna ilişkin bu yüksek bulgunun yaşlılar için önemli bir risk teşkil ettiği dikkat çekmektedir.

\section{Sonuç ve Öneriler}

Yaşlanan kadınlar; değişen aile yapısı, emeklilik ve ekonomik gelir, toplumsal ilişkiler, dul kalma ve yas, fizyolojik ve psikolojik sağlıktaki değişiklikler dolayısıyla başarılı yaşlanma sürecini erkeklere nazaran farklı deneyimlemektedir. Pinquart ve Sörensen’in (2001) öznel iyi oluş perspektifinden yaşlılıkta cinsiyet farklılıklarını gözden geçirdiği çalışmaya göre, kadınlarda morbidite oranı erkeklere göre daha yüksektir; bu da sağlık açısından olası dezavantaja işaret etmektedir. Daha uzun yaşam süreleri nedeniyle yaşlı kadınların dul kalma olasılığı yaşlı erkeklere göre daha yüksektir. Ayrıca yaşlı kadınlar, yaşamın erken dönemlerinde yaşanan eşitsizlikler nedeniyle daha az maddi kaynağa sahiptir (Dannefer, 2003; Stein ve Moritz, 1999). Araştırmada ilerleyen yaşla birlikte daha fazla kadının, muhtemelen yaşla sosyal prestij kazanan erkeklere kıyasla kendilerini daha az çekici bulduğu görülmektedir. Tüm bu 
değiş̧iklikler, yaşlı kadınların yaşlandıkça daha az güvende hissetmelerine neden olmaktadır. Bu veriler kadınların yaşlanma süreçlerinin cinsiyet ve toplumsal cinsiyet özelliklerinden etkilendiğini göstermektedir.

Evinde eşiyle birlikte yaşayan yaşlılar, uzun yıllar süren bir düzende yaşamaktadır. Eşleriyle bir arada bulunmanın yaşlılara sosyal destek sunması dolayısıyla yaşlıların başarılı yaşlanmasına katkı sunduğu düşünülebilir. Bununla birlikte eşle yaşamanın yaşlllıkta bakım verme yükümlülüğü getirmesi dolayısıyla özgürlüğü de kısıtlayabileceği düşünülmektedir. Eşin vefatından sonra bakım verme yükümlülüğü biten yaşlıların daha özgür bir düzene geçmesinin alışılan sosyal desteği kaybetmesinin etkilerini azaltmış olabileceği düşünülmektedir. Çocuklarıyla yaşayan yaşlılar da kendi düzenlerinden feragat etme ile sevilen kişilerle bir arada yaşama gibi avantaj ve dezavantajları birlikte deneyimlemektedir. Yaşlıların yaşam biçimlerinin sahip olduğu bu avantaj ve dezavantajların başarılı yaşlanma düzeylerini benzer biçimde etkilediği araştırma sonuçlarıyla desteklense de bu ilişkinin nasıl ve ne yönde anlaşılması için daha derinlemesine bir çalışmaya ihtiyaç duyulduğu görülmektedir.

Biyolojik yaşlanma sürecinde insan vücudunda meydan gelen değiş̧iklik türleri iki tipe ayrılmaktadır. Birincisi fiziksel özelliklerdeki gerilemeyle bağlantılı iken, ikincisi çoklu patoloji olarak adlandırılan ve aynı anda birkaç hastalığın ortaya çıkması anlamına gelen süreçle ilgilidir. Bu durum, organların işlevlerinde kısıtlamalara neden olan metabolik sistemdeki yıkım süreçlerinin yaygınlığından kaynaklanmaktadır. Yaşlanma her birey için kendine özgü değişimler getirmekle birlikte bu dönemde kalp damar sistemi, böbrekler, sindirim sistemi, karaciğer, beyin, sinir sistemi, akciğerler ve endokrin sisteminde değişimler görülmektedir (Hablemitoğlu ve Özmete, 2010). Dolayısıyla yaşlılıkta enfeksiyonlar, solunum ve sindirim hastalıkları, motor ve endokrin sistem hastalıkları çok sık görülmektedir. Yaşlılıkta kemik yoğunluğu da azalmaya başladığı için kemikler zayıflayıp kırılganlaşmaktadır. Seksen beş yaşından 
sonra sık görülen osteoporoz genellikle kemik kırılmalarından sonra fark edilmektedir. Erken müdahale için özellikle kadınlarda altmış beş yaşından itibaren kemik taraması önerilmektedir (The Guide to Clinical Preventive Services, 2014).

Yaşlanan birey fiziksel sağlık sorunlarının yanı sıra mental sağlık sorunlarıyla da karşılaşmaktadır. Bellekte basit bozulmalar, demans ve demansın bir alt türü olan ancak en fazla tanı alan Alzheimer yaşlı bireyin maruz kaldığı mental sağlık sorunları arasında yer almaktadır. Yaşlılıkta bilişsel işlevlerin korunması ve geliştirilmesi için basit tedbirler önerilmektedir. Televizyon izleme süresinin azaltılması ve hatta tamamen kapatılması, yeni şeyler öğrenilmesi veya bilinen herhangi bir şeyin yeni bir yol izlenerek yapılması, yürüyüş ve bahçecilik gibi basit fiziksel aktivitelerin düzenli olarak yapılmasıyla beyin işlevlerinin korunumuna katkı sağlanabilmektedir (NRTA: AARP's Educator Community, 2009). Nöronların yavaş yavaş azaldığı ve yeniden üretildiği sürecin başlarında yeni nöronlar arasındaki bağlantıların güçlendirilmesi ve yaşlanmaya dair etkilerin azaltılması için daha erken yaşlardan itibaren yaşam biçimlerinin aktif hale getirilmesi önerilmektedir. Özellikle emeklilikle birlikte pasifleşen yaşlı bireylerin daha aktif bir biçimde yaşama katılması için gerekli önlemlerin alınması önemli bulunmaktadır.

Kadın ve erkek yaşlıların nasıl bir yaşlanma süreci geçirdiğini, başarılı yaşlanma sürecinin cinsiyete göre nasıl şekillendiğini detaylı bir biçimde inceleyecek nitel ve nicel çalışmaların gerçekleştirilmesi önemli görülmektedir. Yaşlılıkta cinsiyetin etkilerinin incelenmesi için her iki grupla ayrı ayrı çalışmaların gerçekleştirilmesi önerilebilir. Erkek yaşlılara ulaşmak için genellikle erkeklerin bulunduğu camilere ya da kıraathanelere ulaşılması ve hatta bu mekânlara gelen yaşlıların yaşlanma durumuna ilişkin özel araştırmaların gerçekleştirilmesi düşünülebilir. Kadın yaşlıların deneyimlerinin derinlemesine ve genellenebilir sonuçlarına ulaşmak için karma yöntemli araştırmaların kurgulanması önerilebilir.

Yaşlıların başarılı yaşlanma düzeylerinin arttırılması açısından psikolojik danışma çalışmalarının etkili olduğu bilinmektedir 
(Demir-Çelebi, 2020). Başarılı yaşlanmaya yönelik programların içerikleri incelendiğinde oturumlara konu olan başlıkların başarılı yaşlanmaya hazırlık, fiziksel aktivite, beslenme ve diyet, süreğen hastalıkları önleme ve yönetme, duygusal sağlık ve stresle başa çıkma, bilişsel işlev eğitimi, aile ilişkileri, ekonomik güvence, araba kullanma, yaşamın sonuna hazırlık ve internet kullanımı şeklinde oluştuğu görülmektedir (Home Instead, 2014; Hsu vd., 2018). Bu veriler göz önünde bulundurulduğunda başarılı yaşlanma programlarının etkililiğinin arttırılması için sistemler arası iş birliğinin sağlanması ve yüz yüze danışma ortamlarının oluşturulması önerilmektedir.

Yaşlılara sunulan hizmetlerin nitelik ve niceliksel olarak iyileştirilmesi, yaşlı nüfusun üretime katkı sunması için yerel yönetimlerin aktif hale gelmesi, bunun için gerekli ve sadece yaşlıya hizmet veren birimlerin oluşturulması önemli bulunmaktadır. Yerel yönetimlerin Dünya Sağlık Örgütü (2007) tarafindan yayınlanan, yaşlılar için yaşanabilir kentler ölçütlerini incelemesi ve kentleri yaşlı vatandaşın huzurla yaşayabileceği yerler haline getirmek için gerekli çalışmaları gerçekleştirmesi, böylece "Yaş Dostu Kent" unvanı alması önerilmektedir.

\section{Kaynakça}

Aksüllü, N. ve Doğan, S. (2004). Huzurevinde ve evde yaşayan yaşlılarda algılanan sosyal destek etkenleri ile depresyon arasındaki ilişki. Anatolian Journal of Psychiatry, 5, 76-84.

Ançel, G. (2007). Depresyon ve hemşirelik bakımı. N. Albayrak, S. İlhan-Erkal, G. Ançel, S.A. Albayrak. (Ed.) Hemşirelik bakım planları (dahiliye-cerrahi hemşireliği ve psiko-sosyal boyut) içinde (s. 67-77). Alter.

Arpacı, F. ve Eroy, A. F. (2012). Yaşlı bakımı ve yaşlılıkta sağlıklı beslenme. H. Bacanlı ve Ş. Işık Terzi (Ed.). Yetişkinlik ve yaşlılık gelişimi ve psikolojisi içinde. Açılım.

Arun, Ö. ve Pamuk, D. (2014). Kurumsal bakım sektöründe ageism: Yaşlı bakım personelinin yaşlanma ve yaşlılıga ilişsin ayrımcı tutumlarının nedenleri ve müdahale önerileri. Mediterranean Journal of $\mathrm{Hu}$ manities, 4(2), 19-33. 
Baral-Kulaksızoğlu, I., Yücel, N., Akyüz, H. A. ve Ekşioğlu, R. N. (2012). Yaşlıya psikolojik destek kitabl: Huzurevi ve bakımevi çalışanları için rehber. İstanbul Büyükşehir Belediyesi.

Billig, N. (2000). Üçüncü bahar yaşlllık ve bilgelik. Evrim.

Bowling, A., ve Dieppe, P. (2005). What is successful ageing and who should define it? BMJ, 331, 24- 31.

Butler, R. N. (1989). Dispelling ageism: The cross-cutting intervention. American Academy of Political and Social Sciences, 503(1), 138-147.

Buz, S. (2009). Göç ve kentleşme sürecinde kadınların "görünürlüğü". Aile ve Toplum, 5(17), 40-50.

Bülöw, M. H. ve Söderqvist, T. (2014). Successful aging: A historical overview and critical analysis of a successful concept. Journal of Aging Studies, 31, 139- 149.

Cinsel Eğitim Tedavi ve Araştırma Derneği. (2006). Cinsel Yaşam ve Sorunları. (Rapor No: 1). Şahin, D., Şimşek F. ve Seyisoğlu, H.: Editör.

Cosman, F., de Beur, S.J., LeBoff, M.S., Lewiecki, E. M., Tanner, B., Randall, S. ve Lindsay, R. (2014). Clinician's guide to prevention and treatment of osteoporosis. Osteoporos Int, 25, 2359-2381.

Çavuşoğlu, Ç. ve Demirkol, M.E. (2018). Yaşlılarda bağımlılık. Bağımlılık Dergisi, 19(3), 59-69.

Çetin Gündüz, H. (2020). Toplumsal cinsiyet ve eğitime yansımaları. Ö. Haskan Avcı. (Ed.). Toplumsal cinsiyet. içinde (s.229-277). Nobel.

Dannefer, D. (2003). Cumulative advantage/disadvantage and the life course: Crossfertilizing age and social science theory. Journal of Gerontology: Social Sciences, 58B(6): 327-337.

Demir-Çelebi, Ç. (2019). Yaşlılık dönemi uyum sorunları. Ş. Baytemur (Ed). Yaşam dönemleri ve uyum sorunları içinde. Nobel.

Demir-Çelebi, Ç. ve Yüksel, M. (2018, Ekim). Yaşlıların başarılı yaşlanma algısı: Bir fenomenolojik araştırma. 8th International Social and Applied Gerontology Symposium, Antalya, Türkiye.

Depp, A. C., Harmell, A. ve Vahia, I. V. (2012). Successful cognitive aging. Behav Neurosci, 10, 35-50.

Duru, G. ve Özdemir, L. (2009). Yaşlı intiharları, nedenleri ve önleyici uygulamalar. Hacettepe Üniversitesi Sağllk Bilimleri Fakültesi Dergisi, 16, 34-41.

Dünya Sağlık Örgütü. (2007). Global age-friendly cities: A guide. https:// www.who.int/ageing/publications/Global age friendly cities Guide English.pdf adresinden 17/10/2019 tarihinde erişilmiştir. 
Dünya Sağlık Örgütü. (2018). Ageing and health. https://www.who.int/newsroom/fact-sheets/detail/ ageing-and-health adresinden 26/07/2019 tarihinde edinilmiştir.

Ebner, N. C. ve Freund., A. M. (2007). Personality theories of successful aging. in Handbook of gerontology: Evidence-based approaches to theory, practice, and policy. J. A. Blackburn \& C. N. Dulmus (Eds.). John Wiley \& Sons.

Efe, A. ve Aydemir, M. (2015). Yaşlı kadın olmak: Psiko-sosyolojik kuramlar çerçevesinde yaşlılık ve kadın - Isparta Huzurevi örneği. Süleyman Demirel Üniversitesi İlahiyat Fakültesi Dergisi, 34(1), 193-223.

Erikson, E. H. (1984). İnsanın sekiz çă̆ı. Toplum.

García, R. F. B., Cassinello, M. D. Z., Bravo, M. D. L., Martínez, M. A. M., Nicolás, J. D., López, P. M. ve Moral, R. S. (2011). Successful ageing: Criteria and predictors. Psychology in Spain, 15(1), 94-101.

Ginsberg, T. B., Pomerantz, S. C. ve Kramer-Feeley, V. (2005). Sexuality in older adults: Behaviours and preferences. Age and Ageing, 34, $475-480$.

Gökçe Kutsal, Y. ve Bal, (t.y.). Yaşlılık ve kadın sağlığı. https://www.huzurevleri.org.tr/docs/gokce kutsal bal yaslilik ve kadin_sagligi.pdf adresinden 06/05/2021 tarihinde erişilmiştir.

Greene, V. I. (1997). Economic contributions of the elderly to society: Generational fairness reconsidered. Paper presented in the Symposium on Positive Contributions of the Elderly to Society, World Congress of Gerontology, Adelaide.

Gridley, H. Browning, C., Gething, L. Helmes, E., Luszcz, M. Turner, J., ... Turner, C. (2000). Psychology and Ageing. A Position Paper prepared for The Australian Psychological Society. https://www.psychology. org.au/getmedia/65d7bcf7-dcfb-400a-dcfb70d-8d436b769fa0/PositionPaper-Ageing.pdf.pdf adresinden 21/07/2019 tarihinde edinilmiştir.

Gridley, H. Browning, C., Gething, L. Helmes, E., Luszcz, M. Turner, J., ... Turner, C. (2000). Psychology and Ageing. A Position Paper prepared for The Australian Psychological Society. https://www.psychology. org.au/getmedia/65d7bcf7-dcfb-400a-dcfb70d-8d436b769fa0/PositionPaper-Ageing.pdf.pdf adresinden 21/07/2019 tarihinde erişilmiştir.

Gürsu, G. (2005). Yaşlılıkta Estetik-Güzellik Kavramları ve Estetik Plastik Cerrahi. Yaşlanan Kadın Sempozyumu'nda sunulan sözlü bildiri. http://www.gebam.hacettepe.edu.tr/yayinlar/yaslanankadin.pdf adresinden 06/05/2021 tarihinde erişilmiştir. 
Hablemitoğlu, Ş. ve Özmete, E. (2010). Yaşlı refahı: Yaşlılar için sosyal hizmet. Kilit.

Hanson, M. ve Gutheil, I. A. (2004). Motivational strategies with alcoholinvolved older adults: Implications for social work practices. Social Work, 49(3), 364- 373.

Hewstone, M., Fincham, D. F. ve Foster, J. (2005). Adolescence and adulthoos. in M. Hewstone, D. F. Fincham \& J. Foster (Eds.). Psychology. Wiley.

Home Instead. (2014). An action plan for successful aging. https://www. caregiverstress.com/wp-content/uploads/2014/07/4070 Aging Plan US Web.pdf adresinden 12/10/2019 tarihinde erişilmiştir.

Hsu, H. C. (2005). Gender disparity of successful aging in Taiwan. Women Health, 42, 1-21.

Hsu, H-C., Chuang, S-H., Hsu, S-W., Tung, H-J., Chang, S-C., Lee, M-M., ... Po, A-T. (2019). Evaluation of a successful aging promotion intervention program for middle-aged adults in Taiwan. Global Health Promotion, 1757975917702087. https://doi.org/10.1177/17579759177020 87Arbuckle, N. W., \& de Vries, B. (1995). Long-term effects of later life spousal and parental bereavement on personal functioning. The Gerontologist, 35, 637-647.

İlgar, L. (2008). Yaşlılık dönemi sosyal özellikleri ve serbest zaman etkinlikleri. K. Ersanlı ve M. Kalkan (Ed.). Psikolojik Sosyal ve Bedensel Açıdan Yaşlılık. içinde. PegemA.

İnce-Güney, Y. (2014). Gender and urban space: An examination of a small Anatolian city. ITU A|Z, 11(2), 153-172.

Kahn, R. L. (2004). Successful aging: Myth or reality. https://deepblue.lib. umich.edu/bitstream/handle/2027.42/49494/2004\%20Winkelman\%20 Lecture $\% 20$ Kahn.pdf?sequence $=3$ adresinden 20/05/2021 tarihinde erişilmiştir.

Karlin, B. E. ve Fuller, J. D. (2007). Meeting the mental health needs of older adults. Implications for primary care practice. Geriatrics, 62, 26-35.

Köroğlu, C. Z. ve Köroğlu, M. A. (2015). Mekânın dönüşümü ve yaşlılık üzerine: kentleşme ve yaşlılık olgusu. Uluslararası Sosyal Araştırmalar Dergisi, 8(41), 812- 821.

Luhmann, M., Hofmann, W., Eid, M. ve Lucas, R. E. (2012). Subjective wellbeing and adaptation to life events: a meta-analysis. Journal of Personality and Social Psychology, 102(3), 592-615. 
Maccora, J., Peters, R. ve Anstey, K. (2018). Gender differences in successful aging: Longitudinal memory resilience in an Australian cohort. Innovation in Aging, 2(Suppl 1), 881-882. doi:10.1093/geroni/igy031.3289

Montross, L. P., Depp, C., Daly, J., Reichstadt, J., Golsban, S., Moore, D., Sitzer, D. ve Jeste, D. V. (2006). Correlates of self-rated successful aging among community-dwelling older adults. Geriatr Psychiatry, $14(1), 43-51$.

Mroczek, B., Kurpas, D., Gronowska, M. ve Kotwas, A. (2013). Psychosexual needs and sexual behaviors of nursing care home residents. Archives of Gerontology and Geriatrics, 57, 32-38.

Nosraty, L., Sarkeala, T., Hervonen, A. ve Jylha, M. (2012). Is there successful aging for nonagenarians? The vitality 90+ study. Journal of Aging Research, 1-9.

NRTA: AARP's Educator Community. (2009). Successful aging and your brain. Report.

NRTA: AARP's Educator Community. (2009). Successful aging and your brain. Report.

Osborne, J. W. (2012). Psychological Effects of the Transition to Retirement. Canadian Journal of Counselling and Psychotherapy, 46(1), 45-58.

Özçakır, A. (2016). Sağlıklı yaşlanma ve kadın. Turkish Family Physician, $3(1), 39-42$.

Özkayar, N. ve Arıŏul, S. (2007). Yaşlanma ile meydana gelen fizyolojik değişiklikler. $\dot{I}_{c ̧}$ Hastalıkları Dergisi, 14(1), 18-26.

Park, S. M., Jang, S. ve Kim, D. H. (2009). Gender differences as factors in successful ageing: A focus on socioeconomic status. Journal of Biosocial Science, 42(1), 99-111.

Pinquart, M. \& Sörensen, S. (2001). Gender differences in self-concept and psychological well-being in old age: A meta-analysis. Journal of Gerontology: Psychological Sciences 56B, 195-213.

Prudential. (2015). Ageless: A Prescription for Successful Aging Research Paper. http://research.prudential.com/documents/rp/Ageless_Research_Paper_FINALCopy_Generic.pdf adresinden 10/08/2017 tarihinde erişilmiştir.

Reichstadt, J., Sengupta, G., Depp, C. A., Palinkas, L.A. ve Jeste, D. V. (2010). Older adults' perspectives on successful aging: Qualitative interviews. Am J Geriatr Psychiatry, 18(7), 567-575.

Rowe, J. W. ve Kahn, R. L. (1987). Human aging: Usual and successful. Science, 237 (4811), 143-149. 
Rowe, J. W. ve Kahn, R. L. (1997). Successful aging. The Gerontologist, 37 (4), 433-440.

Rybash, J. M., Roodin, P. A. \&Santrock, J. W. (1991). Adult Development and Aging. Wm. C. Brown.

Schmid, W. (2018). Anne baba ve büyükanne büyükbaba olmanın sevinçleri üzerine. İletişim.

Sharpley, C. F. ve Layton, R. (1998). Effects of age of retirement, reason for retirement, and pre-retirement training on psychological and physical health during retirement. Australian Psychologist, 33, 119-124.

Sharpley, C. F., Gordon, R. M. ve Jacobs, N. (1996). Results of a survey of adjustment to retirement. Melbourne: Centre for Stress Management and Research, Monash University.

Shear, M. K., Ghesquiere, A. ve Glickman, K. (2013). Bereavement and complicated grief. Curr Psychiatry Rep., 15(11), 206-19.

Silverstein, M. \& Giarrusso, R. (2010). Aging and family life: a decade review. J Marriage Fam., 72(5), 1039-58.

Slater, R. (1995). The epsychology of growing old: Looking forward. Open University.

Stambuck, A. (2019). Widowhood and grieving in old age. Socialno delo, $58(2), 125-144$.

Stein, C., Moritz, I. (1999). A life course perspective of maintaining independence in older age. Guidance of WHO Aging \& Health. Geneva: World Health Organization, WHO/HSC/AHE/99.2.

Swindell, R. ve Vassella, K. (1999). Money talks: Ascribing a dollar value to volunteerism in Australian and New Zealand U3As. Australasian Journal on Ageing, 18, 19-22

Tarhan, S. (2020). Mesleki rehberlik bağlamında toplumsal cinsiyet ve çalışma hayatı. Ö. Haskan Avcı (Ed.). Toplumsal Cinsiyet içinde (s.277317). Nobel.

Taşkın, M. ve Akçay, S. (2019). Torunlarına bakan büyükannelerin deneyimlerine ilişkin nitel bir araştırma. Toplum ve Sosyal Hizmet, 30 (2), 583-606.

Terakye, G. ve Güner, P. (1992). Kriz potansiyeli taşıyan bir dönem: Yaşlılık. Kriz Dergisi, 5(2).

The Guide to Clinical Preventive Services 2014: Recommendations of the U.S. Preventive Services Task Force. Rockville (MD): Agency for 
Healthcare Research and Quality (US); 2014 May. Available from: https://www.ncbi.nlm.nih.gov/books/NBK235846/

Thielke, S. ve Diehr, P. (2012). Transitions among health states using 12 measures of successful aging in men and women: Results from the Cardiovascular Health Study. Journal of Aging Research, 1-9.

Thomas, S. A., Browning, C. J. ve Greenwood, K. M. (1995). Rehabilitation of older injured workers. Disability and Rehabilitation, 16, 162-170.

Türkiye İstatistik Kurumu. (2020). İstatistiklerle Yaşlllar, 2019. https:// data.tuik.gov.tr/Bulten/Index?p=Istatistiklerle-Yaslilar-2019-33712 adresinden 03/05/2021 tarihinde erişilmiştir.

Uğur, S. B. (2018). Torun bakım faaliyetinin bakım sağlayıcı büyükannelerin sağlık durumları üzerindeki etkisi. Antalya: Mediterranean Journal of Humanities Dergisi, 8(1), 399-415.

United Nations Division for the Advancement of Women Department of Economic and Social Affairs. (2002). Gender dimensions of ageing. https://www.un.org/ womenwatch/daw/public/ageing-final.pdf adresinden 30/07/2019 tarihinde erişilmiştir.

Utz, R. L., Carr, D., Nesse, R. ve Wortman, C. B. (2002). The effect of widowhood on older adults' social participation: An evaluation of activity, disengagement, and continuity theories. The Gerontologist, 42(4), $522-533$.

Wells, Y. D. ve Kendig, H. L. (1997). Health and well-being of spouse caregivers and the widowed. The Gerontologist, 37, 666-674

Whitbourne, S. K. (2001). Adult development and aging: Biopsychosocial perspectives. John Wiley \& Sons.

Wolcott, I. (1998). Families in late life: Dimensions of retirement. Working paper No 14. Melbourne: Australian Institute of Family Studies.

Yörükan, T. ve Yörükan, A. (2005). Insanca yaşamak için şehir ve konut. İstanbul: Babil.

Yüksel, M. ve Demir Çelebi, Ç. (2019). Büyükanne ve büyükbabalar için psikoeğitim programı: Bir eylem araştirması örneği. 8th International Social and Applied Gerontology Symposium, Antalya, Türkiye. 